\title{
INTERCONNECTION OF A PHOTOVOLTAIC GENERATOR (PVG) TO A MAIN SUPPLY: A SIMULATION STUDY
}

\author{
Maamar Taleb \\ University of Bahrain \\ Department of Electrical and Electronics Engineering \\ P.O.Box 32038, ISA Town \\ Bahrain \\ Phone: +973 39151520, Email: maamar@eng.uob.bh
}

\begin{abstract}
This paper presents a technique for interconnecting a photovoltaic generator (PVG) to a main supply of AC nature. The technique uses a single phase full wave bridge rectifier. Such bridge rectifier is operated in an inverter mode of operation. and that is to guaranty its contribution of real power to a main AC supply. The bridge rectifier is also operated in such a way that its control circuit (i.e triggering circuit) is self adjusted when extracting the maximum power from the $P V G$ and injecting such power into to the main AC supply. The proposed technique has been formulated by a MATLAB/SIMULINK model. The simulation of the developed simulink model shows for a certain pre-defined AC load that up to $66.39 \%$ of the power required by an $A C$ load is obtained from the $P V G$ source. The remaining $33.61 \%$ of power required by the AC load is provided by the main AC supply. The Simulink model shows also that nearly $99.14 \%$ of power can be extracted from the PVG source at a certain pretended solar radiation level (i.e insolation level).
\end{abstract}

Key words: Integration of Renewable Energy Sources to Grid Systems, Photovoltaic Generation System, Maximum Power Point Tracker, AC/DC Converter Applications, MATLAB/SIMULINK Applications.

\section{Introduction}

It is well known that most (if not all) renewable energy resources suffer from the lack of providing constant power when the surrounding weather and environmental conditions change. Due to such non-constant power provision characteristic, storage batteries are traditionally employed in parallel with the renewable energy resources and that is to supply any deficiency or to absorb any excess in load energy requirements. Unfortunately, the storage batteries are characterized by an additional considerable cost to renewable energy resources cost. Moreover, the storage batteries have also a short life time when compared to the life time of the renewable energy resources. A wise solution to overcome the problem of relying totally on the power generated only by the renewable energy resources is to constitute a hybrid DC grid that should contain or connect all renewable energy resources plus storage units (storage batteries + fly wheels) in parallel and interconnecting such hybrid DC grid to the $\mathrm{AC}$ grid using power inverter [1] modules. A glance at the anticipated task from such proposed solution is that at any time of operation and for any prospective energy load demand the energy is guarantied from the DC grid as well as from the $\mathrm{AC}$ grid. One should note that it will be nice to use the $\mathrm{AC}$ grid whenever there is deficiency in energy from the hybrid DC grid. The ultimate goal of the proposed solution is to ease the constraint on relying totally on the storage batteries. The realization of the objective of the above proposed solution necessitates the development of advanced and smart power flow controllers. Such controllers may turn-out to be expensive and may not be flexible to certain modes of operation.

This paper continues the exploration of the author's idea reported in reference [2] which proposed a practical alternative to interconnect a PVG source to a main AC supply. Unfortunately, the author [2] had tried his work at a relatively low power ratings an more importantly he had not targeted the maximum extraction of power from the PVG source. That was due to the fact that he has operated his experimental setup on an open loop control way. This present contribution introduces a selfadjusted firing angle controller that can be attributed the term: maximum power point tracker and which is operated in closed loop format while targeting the maximum extraction of power the PVG source.

The work is done in the Matlab/Simulink environment and the simulation results prove the effectiveness of the tracker under a number of pretended insolation levels.

\section{2- Study System}

A general scheme of the study system is represented in figure 1. The desired powers flow is simplified in figure 1(a). Figure 1(b) consists of four main parts: An $\mathrm{AC}$ voltage source representing a $50 \mathrm{~Hz}$ main supply in series with a pretended equivalent source inductance, an $\mathrm{AC}$ load requiring a constant power and it is connected at a point refereed to usually in the literature by the term: point of common coupling (PCC), a bridge rectifier in series with a reactance representing the inductance of a power transformer, and a DC voltage source consisting of a PVG source in series with a reactor. The polarity of the PVG is reversed in the figure and that is to indicate that the PVG will be generating power rather than absorbing power. The bridge rectifier is controlled by a firing angle controller. The next subsections describe the PVG model and the contents of the important blocks of figure 1 . 


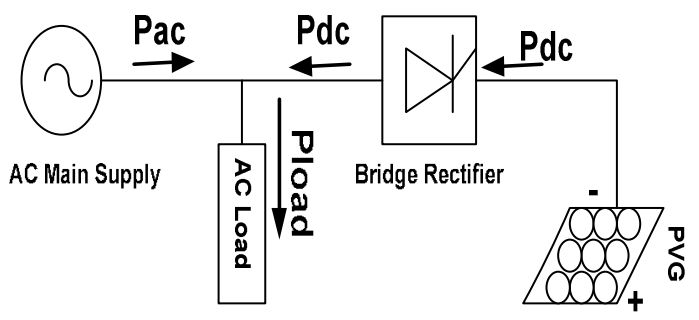

(a)

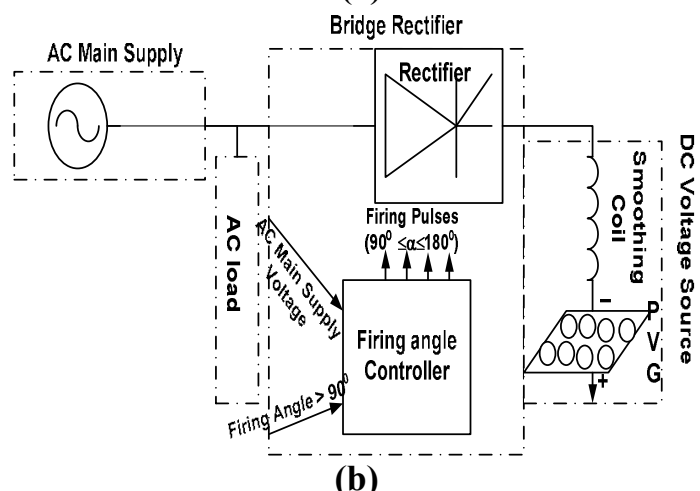

(b)

Figure 1: Study System

\section{2-1 Photovoltaic Generator (PVG) Model}

The photovoltaic generator (PVG) is an array of solar cells combined in series and parallel to provide a certain level of voltage and current. The voltage and current values are dependent on the prospective element that will be connected across the PVG external terminals. The PVG model does not differ in origin from the solar cell model. As to the solar cell model, it can be found in any physics or microelectronics textbook dealing with semiconductor devices. In this investigation, the PVG model is taken from reference [3]. Such PVG model is reproduced in the form of:

$$
V_{g}=-0.9 I_{g}+\frac{1}{0.0422} \ln \left(1+\frac{I_{p h}-I_{g}}{0.0081}\right)
$$

where

$\mathbf{I}_{\mathbf{p h}}$ : photocurrent that is proportional to the insolation level

$\mathbf{I}_{\mathbf{g}}$ : PVG supplied current

$\mathbf{V}_{\mathbf{g}}$ : PVG source voltage

Such PVG model has been converted to another model called Akbaba Model [4]. Akbaba Model of the PVG generator is of the form:

$$
I_{g}=\frac{\left(V o c-V_{g}\right)}{A+B V_{g}{ }^{2}-C V_{g}}
$$

where

Voc: open circuit voltage across the terminals of the PVG generator at an insolation level

A, B, C: are parameters whose values depend on the insolation level. Such values can be easily tabulated by performing simple laboratory tests. The values of Voc, A, $\mathbf{B}, \mathbf{C}$ as well as the photocurrent $\mathbf{I}_{\mathbf{p h}}$ of the used PVG in this investigation are provided in Table A-1 of the
Appendix. The way of tabulating such parameters is documented in the text of reference [4].

Akbaba PVG model of equation (2) is extended here to represent the PVG by a voltage source model rather than a current source model. Such voltage source model is of the form:

$$
V_{g}=\frac{\left(C I_{g}-1\right)+\sqrt{\left(1-C I_{g}\right)^{2}+4 B I_{g}\left(V o c-A I_{g}\right)}}{2 B I_{g}}
$$

The $I_{g}-V_{g}$ characteristics of the PVG source at different sun insolation levels $(100 \%, 90 \%, 80 \%, 70 \%, 60 \%$ levels from top to bottom) are depicted in figure 2 (a). For a specified insolation level, the voltage $V_{g}$ times the current $I_{g}$ determines the power that can be generated from the PVG source.

$$
P_{g}=V_{g} I_{g}=\frac{V_{g}\left(V O C-V_{g}\right)}{A+B V_{g}^{2}-C V_{g}}
$$
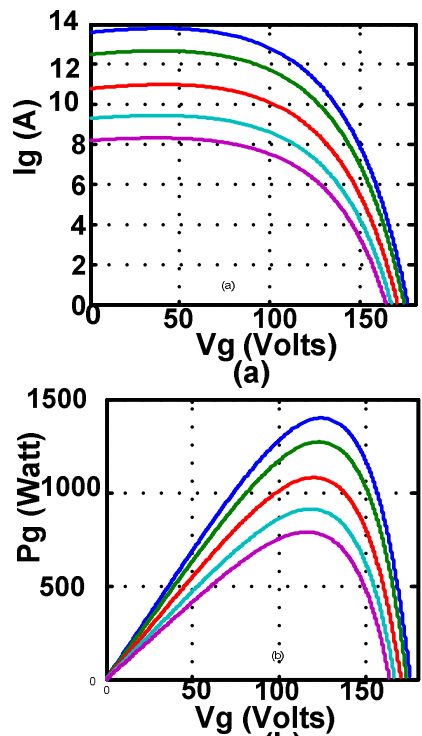

(b)

Figure 2: PVG Characteristics a) I-V Characteristics b) P-V characteristics

This calculations of such power are depicted in figure 2 (b) for different insolation levels (i.e $100 \%, 90 \%, 80 \%$, $70 \%, 60 \%$ levels from top to bottom).

As it is seen in figure 2(b) the power curves exhibit maximums at certain voltage $V g$. The maximum power points are desired to be reached in this investigation and that will constitute one of main duties or targets of the firing angle controller module of figure 1.

\section{2-2 Bridge Rectifier:}

The bridge rectifier is no more than four power thyristors connected as shown in figure 3 . The rectifier should operate in an inverter mode of operation [5]. This means that the firing angle provided to the valves of the bridge should be greater than $90^{\circ}$. Understanding and analyzing a bridge rectifier working under an inverter mode of operation is well documented in chapter 6 of reference [5] and more importantly one can easily note 
that the average value of the voltage at the dc side obeys the following expression [5]:

$$
V_{D C}=K_{1} \cos (\alpha)-K_{2} L_{S}
$$

In which

$\mathbf{K}_{\mathbf{1}}$ : is a positive constant that depends on the rms value of the main supply voltage

$\alpha$ : is the firing angle

$\mathbf{K}_{\mathbf{2}}$ : is a positive constant that depends also on the value of the frequency of the main supply voltage .

$\mathbf{L}_{\mathbf{S}}$ : is the total value of the source and the transformer inductances that will create the commutation phenomenon in bridge rectifiers.

It is clear that for any value of the firing angle greater than $90^{\circ}$, the average voltage $\mathrm{V}_{\mathrm{DC}}$ is negative.

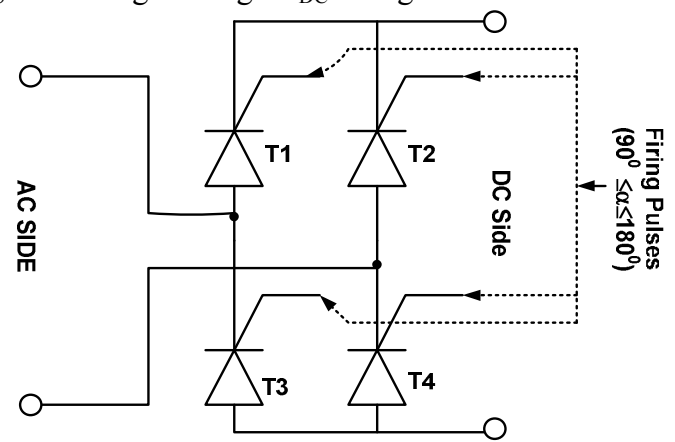

Figure 3: Single Phase Full wave Bridge Rectifier working in an inverter Mode of Operation

\section{2-3 Firing Angle Controller:}

The proposed firing angle controller of the bridge rectifier of figure 3 is shown in figure 4 . Figure $4(a)$ is made of two blocks. The first block of figure 4(a) serves at finding and adjusting the on-line firing angle that guaranties a maximum extraction of power from the PVG source for a pre-set insolation level while the second block of the same figure (figure 4(a)) generates pulses that start at the firing angle (such angle is estimated by the first block and it should be greater than $90^{\circ}$ ) and end up at the next zero crossing of the PCC voltage waveform. Contents of the two blocks of figure 4(a) are further detailed in figure 4(b) and 4(c) respectively.

To explain how the firing angle control block diagram performs its job, pretend the system is initially working under certain steady state conditions. That is the firing angle corresponding to a certain desired $\mathrm{PVG}$ power (Pg,max) value is pre-determined. The desired $\mathrm{PVG}$ power (Pg,max) is the value of the maximum power that can be extracted from the PVG source at a certain insolation level. The relation between the insolation level and the maximum PVG power (Pg,max) is the contents of left upper block of figure 4(b). The analysis that is behind the development of such relation is detailed in part A. 2 of the appendix in this paper. Actually, the maximum power (Pg,max) at a specified insolation level is more than finding the maximum of equation (4).

Now let us say there is a change in the insolation level. Such change indicates that there is a need to update the desired PVG power (Pg,max). By taking the absolute value of the probed power $\left(\mathrm{P}_{\mathrm{D}}\right)$ at the $\mathrm{DC}$ side of figure 1 and subtracting from a new desired PVG power (Pg,max), an error is tabulated. The absolute value of the error is checked whether it is between certain pre-set limits or not. In the case of having an error beyond the pre-set limits (and this is an often case encountered or expected when starting any initial simulation), a product of a nonzero value with the sign of the tabulated error is integrated and amplified. The output of the integrator is bounded between $90^{\circ}$ and $180^{\circ}$. This is possible through the use of the limiter block that can be either allocated in the integrator block or cascaded with the integrator of figure 4(b). The firing angle (i.e output of figure 4(b)) is converted to a certain voltage level by the upper left block of figure 4(c). The voltage level is compared with the level of a saw tooth signal. The frequency of the saw tooth signal is $100 \mathrm{HZ}$ and it is synchronized with the PCC voltage waveform.

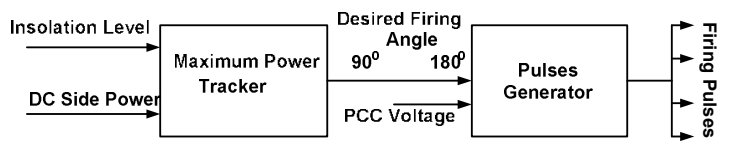

(a)

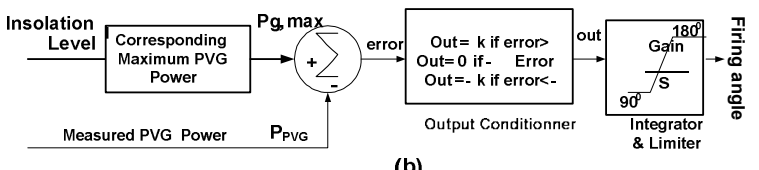

(b)

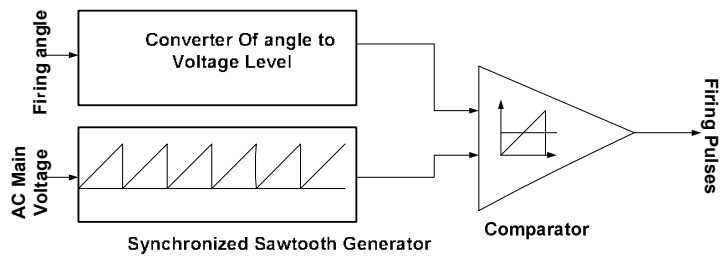

(c)

Figure 4: Firing Angle Controller a) General Block Diagram b) Maximum Power Point Tracker c) Firing Pulses Generator

Whenever the voltage level exceeds the saw tooth signal, there will be a generation of a pulse at the output of the comparator block diagram of figure 4(c). This pulse is fed to the gates of the SCRs of the bridge rectifier of figure 1 . The previous process is repeated dynamically until the error of figure 4(b) decreases and tends to be zero or is within certain tolerance limits. This means that the firing angle value keeps changing automatically as the insolation level changes.

In summary, the firing angle controller should perform two tasks consequently:

i. generate firing pulses to the thyristors of the bridge rectifier between $90^{\circ}$ and $180^{\circ}$ and that after detecting the zero crossing of the PCC voltage waveform

ii. generated pulses at instants that correspond to the extraction of maximum power from the PVG source.

\section{3- System Performance}

The performance of the proposed technique of figure 1 has been evaluated or simulated using MATLAB/SIMULINK [6]. Figure A.1 of the appendix is the developed model for the system under study. The system data used in the simulations is provided in the appendix (Tables A-1 and A.2). The performance looked 
for, when running the SIMULINK block of figure A.1, consists of measuring the power consumed by the $\mathrm{AC}$ load, power delivered by the AC source and power delivered by the PVG source. Such performance is dynamically tabulated for different pretended insolation levels. Figure 5 visualizes such performance for 5 different levels of insolation.

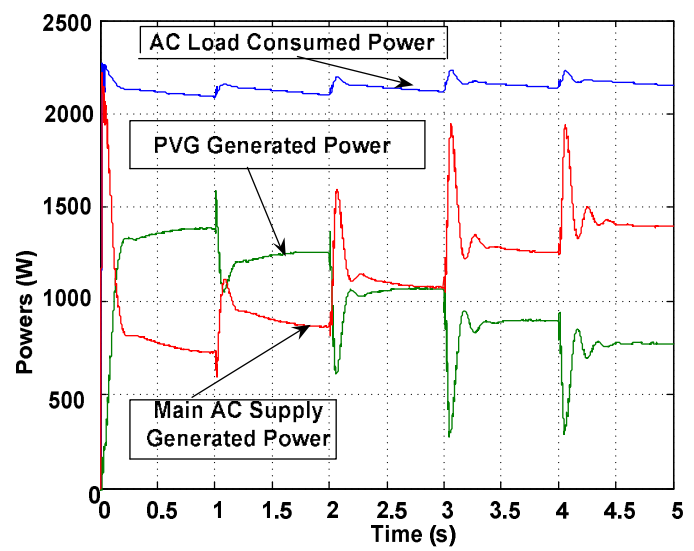

Figure 5: System Performance: Power Generation by PVG and AC Sources, and Consumption by AC Load

One remark that should be raised at this stage (before it may cause an ambiguity to the reader) is that the time coordinate in the $\mathrm{X}$-axis in figure 5 is not a true time of day. It is simply a representation of a particular insolation level. The following table (Table 1) clarifies such ambiguity.

\begin{tabular}{|c|c|c|c|}
\hline $\begin{array}{l}\text { Time } \\
\text { Period }\end{array}$ & $\begin{array}{c}\text { Corresponding } \\
\text { insolation } \\
\text { level } \\
\end{array}$ & $\begin{array}{l}\text { Time } \\
\text { Period }\end{array}$ & $\begin{array}{c}\text { Corresponding } \\
\text { insolation } \\
\text { level }\end{array}$ \\
\hline $0-1$ & $100 \%$ & $3-4$ & $70 \%$ \\
\hline $1-2$ & $90 \%$ & \multirow[t]{2}{*}{$4-5$} & \multirow[t]{2}{*}{$60 \%$} \\
\hline $2-3$ & $80 \%$ & & \\
\hline
\end{tabular}

A close examination of the obtained curves at steady state conditions one can deduce that table 2 presents values or pictures of the power consumed by the AC load, power generated by the PVG sources and the main AC supply for five different insolation levels. The contributions of each generated source to the AC load are also calculated and the results of such calculations are shown in the last two columns of Table2. A glance at the tabulated contributions, one can deduce that nearly $66.39 \%$ of the AC load power is obtained from the PVG source.

When comparing the two curves for every pretended insolation level, one can conclude that nearly all possible generated power by PVG source is extracted at each presumable insolation level. Table 3 indicates the matching factor between the PVG generated powers and the PVG maximum power when steady state conditions are reached from the simulation process.

\begin{tabular}{|c|c|c|c|c|c|}
\hline \multicolumn{6}{|c|}{ Table 2: Power Generation and Consumption } \\
\hline Inso & $\mathrm{AC}$ & PVG & Main & Contrib & Contribut \\
\hline lati & Load & Sourc & Suppl & ution of & ion of \\
\hline on & Cons & $\mathrm{e}$ & $\mathrm{y}$ & PVG & Main AC \\
\hline Lev & umed & Gener & Gener & Source & Supply to \\
\hline el & Powe & ated & ated & to $\mathrm{AC}$ & AC Load \\
\hline$(\%)$ & $\mathrm{r}(\mathrm{W})$ & $\begin{array}{l}\text { Powe } \\
\text { r (W) }\end{array}$ & $\begin{array}{l}\text { Powe } \\
\text { r (W) }\end{array}$ & $\begin{array}{l}\text { Load } \\
(\%)\end{array}$ & $(\%)$ \\
\hline 100 & 2090. & 1388. & 702. & 66.39 & 33.61 \\
\hline 90 & 2101. & 1259. & 841. & 59.93 & 40.07 \\
\hline 80 & 2118 & 1060. & 1057. & 50.09 & 49.91 \\
\hline 70 & 2138 & 892. & 1246. & 41.71 & 58.29 \\
\hline 60 & 2152. & 767. & 1384. & 35.67 & 64.33 \\
\hline
\end{tabular}

As to the question of how much power can be extracted from the PVG source for different insolation levels, figure 6 depicts two curves in this regard. One of the curve represents the maximum power that be extracted from the PVG (i.e such curve is no more than the representation of the left column of Table A.1 of the appendix) while the second curve represents the generated power delivered by the PVG source.

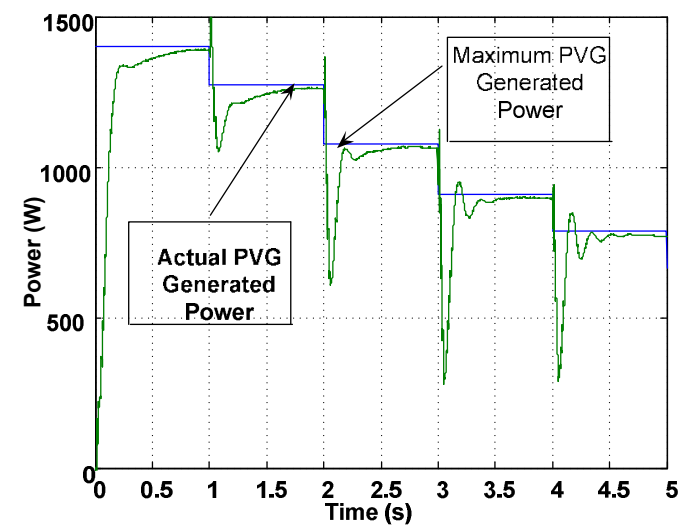

Figure 6: System Performance: Power Generated by the PVG Source and Maximum Power that can be extracted from the PVG source.

\begin{tabular}{|c|c|c|c|}
\hline \multicolumn{4}{|c|}{ Table 3: Matching Factor Between Generated PVG } \\
Power and Maximum PVG Power \\
\hline $\begin{array}{c}\text { Insolation } \\
\text { Level (\%) }\end{array}$ & $\begin{array}{c}\text { PVG Source } \\
\text { Generated } \\
\text { Power (W) }\end{array}$ & $\begin{array}{c}\text { PVG Source } \\
\text { Maximum } \\
\text { Generated } \\
\text { Power (W) }\end{array}$ & $\begin{array}{c}\text { Matching } \\
\text { Factor } \\
(\%)\end{array}$ \\
\hline 100 & 1388.0 & 1400 & 99.14 \\
\hline 90 & 1259.1 & 1272 & 98.98 \\
\hline 80 & 1060.9 & 1077 & 98.50 \\
\hline 70 & 892.6336 & 910.2 & 98.07 \\
\hline 60 & 767.6625 & 784.7 & 97.83 \\
\hline
\end{tabular}

At this point, it is worth mentioning that based on the depicted curves in figures 5 and 6 and on the screened results in Tables 1 and 2, one can conclude that the objectives of this investigation are met when operating the bridge rectifier in the inverter mode.

The drawbacks that might be expected from the implementation of this idea is the confrontation with the power quality issue. Such issue consists of noting the distortion in voltage and current signals at the AC side of 
figure 1. Signal distortion creates adverse effects on the sensitive loads that may replace the resistive load connected at the PCC point. Currents and voltages waveforms are recorded when simulating the developed SIMULINK diagram of figure A.1. Figure 7 visualizes the waveforms of the voltage at the point of common coupling (PCC) at $100 \%$ and $60 \%$ insolation levels. The total harmonic distortion factor (THD) was computed and it was found to be $13.51 \%$ and $9.67 \%$ at $100 \%$ and $60 \%$ insolation respectively. Such results are clearly exceeding the limits set by Power Quality Standards like the well known IEEE standard [7].
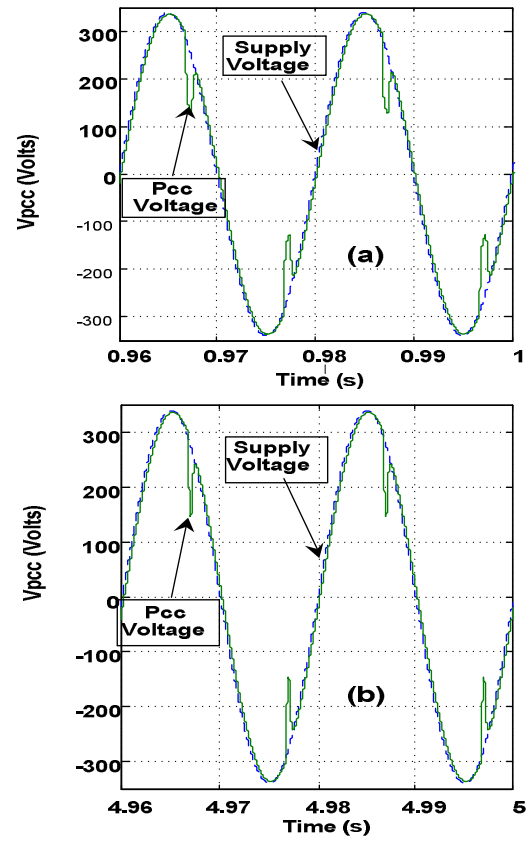

Figure 7: System Performance: PCC Voltage Waveforms a) Under 100\% Insolation Level b) Under 60\% insolation Level.

Figure 8 depicts the main AC supply current and the $\mathrm{AC}$ load currents waveforms at $100 \%$ and $60 \%$ insolation levels. For the main AC supply current, the total harmonic distortion factor (THD) was computed and it was found to be $41.26 \%$ and $27.33 \%$ at $100 \%$ and $60 \%$ insolation respectively. For the load current, the total harmonic distortion factor was found to be $13.51 \%$ and $9.67 \%$ at $100 \%$ and $60 \%$ insolation respectively. current.

The levels of the total harmonic distortion factor encountered whether in the voltage waveforms or in current waveforms exceed the allowed limits stated in a number of standards like standard of reference [7]. Besides the encountered problems with power quality, the power factor at the main AC supply bus was also found to be low, in particular at higher insolation levels when the PVG contributes more power to the AC load. Therefore, future extension of follow up to the current investigation is to come-up with active voltage or current conditioners, and power factor correctors that will serve at reducing the harmonics and improving the power factor level. In doing so, four objectives will be met 1- Effectiveness contribution of the PVG to AC grid systems, 2- Maximum extraction of power from PVG system, 3- Qualitative control of voltage and current waveforms, and 4- Positive improvement of power factor.
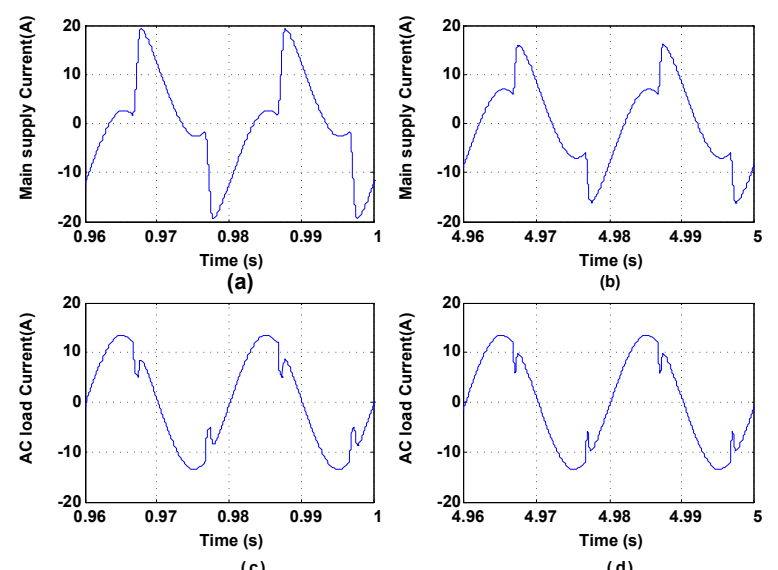

(c)

(d)

Figure 8: System Performance: a) Main AC Supply Current Waveform under 100\% Insolation Level b) Main AC Supply Current Waveform under 60\% insolation Level c) AC Load Current Waveform under 100\% Insolation Level d) AC Load Current Waveform under 60\% insolation Level..

\section{Conclusion}

Interconnecting PVG source to a main AC supply has been investigated in this paper. The interconnection has been done using a bridge rectifier working in the inverter mode of operation.

A Matlab/SIMULINK model for the idea of interconnection has been developed to check the idea claims. Quite encouraging results were reached for five possible insolation levels. For an almost $2 \mathrm{~kW}$ power required by an ac load connected at the ac side of the bridge, the PVG source contributed nearly $66 \%$ of such power while the main ac supply supplied the rest $34 \%$ of power to the AC load. The reader might question such claims but the author would like to clarify that this has occurred because the maximum possible power from the used PVG is $1.4 \mathrm{kw}$ which is comparable to the required AC load $(2 \mathrm{Kw})$. Thus, if the same PVG source is used in other circuits in which the AC load may require $20 \mathrm{kw}$ for instance, the contribution from the PVG source to the source will be at most $(1.4 / 20 * 100=7 \%)$ and the remaining $93 \%$ of load power will be provided by the main AC supply. Similarly, if the same PVG source is used while the $\mathrm{AC}$ load requires only $1 \mathrm{Kw}$ for instance, the PVG will cover $100 \%$ of the AC load power and moreover it will pump $400 \mathrm{~W}$ into the main AC supply.

Besides proving the effectiveness of interconnecting the PVG source to AC grid, maximum power extraction from the PVG source has been also targeted in this investigation for five pretended insolation levels. This has been through a self-adjusted firing angle controller in the MALAB/SIMULINK environment. Simulation results show that a $99 \%$ matching factor between the maximum PVG power and the delivered PVG power are reached at a pretended $100 \%$ insolation level.

The encountered drawback after analyzing the quality of the obtained voltage and current waveforms is the 
generation of tremendous distortion in the concerned waveforms and low power factor levels. Therefore, the last worry is among the tasks or recommendations that will be investigated by the author in the near future.

\section{References}

[1] "IEEE Standard for Interconnecting Distributed Resources with Electric Power Systems. Standard IEEE 1547-2003, "' 2003.

[2] M. Taleb, " Interconnection of a Photovoltaic Generator (PVG) To a Main Supply: A Practical Study", Presented in the International Conference on Renewable Energies and Power Quality (ICREPQ'10), Granada (Spain), 23-25 March, 2010 and published in the Renewable Energy and Power Quality Journal edited by European Association for the Development of Renewable Energies, Environment and Power Quality (EA4EPQ). Vol 8, April 2010.

[3]J. Appelbaum, "The Operation of Loads Powered By Separate Sources or by Common Source of Solar Cells", IEEE Transactions on Energy Conversion, Vol. 4, No. 3, pp. 351-357, September 1989.

[4]M. Akbaba, "Matching of AC loads to PVG for Maximum Power Transfer Using an Enhanced Version of Akbaba Model and Double Step-up Converter", International Journal of Solar Energy, Vol. 75, pp. 17-25, 2003.

[5] N. Mohan, T. M. Undeland, and W. P. Robbins, “ Power Electronics: Converter, Applications, and Design", John Wiley and Sons Inc., New Jersey, 2003.

[6] Matlab. Version 7.01 Release 14, The MathWorks Incorporation, 1984-2002.

[7] IEEE Standard 1159-1995, "Recommended Practice For Monitoring Electric Power Quality".

\section{Appendix}

\section{A.-1: Study System Parameters:}

\begin{tabular}{|c|c|c|c|}
\hline \multicolumn{4}{|c|}{ Table A-1: Used PVG Parameters } \\
\hline $\begin{array}{c}\text { Insolation } \\
\text { Level (\%) }\end{array}$ & $\begin{array}{c}\text { Maximum } \\
\text { PVG } \\
\text { Power } \\
\text { Pg, Max } \\
\text { (W) }\end{array}$ & Photocurrent $^{\text {Open }}$ & $\begin{array}{c}\text { Open } \\
\text { Circuit } \\
\text { Voltage } \\
\text { Voc } \\
\text { (V) }\end{array}$ \\
\hline 100 & 1388.0 & 13.61 & 176 \\
\hline 90 & 1272 & 12.5 & 174 \\
\hline 80 & 1077 & 10.78 & 170.5 \\
\hline 70 & 910.2 & 9.31 & 167 \\
\hline 60 & 784.7 & 8.2 & 164 \\
\hline 50 & 663.7 & 7.08 & 160.5 \\
\hline 40 & 456.6 & 5.15 & 153 \\
& & & \\
\hline
\end{tabular}

\begin{tabular}{|c|c|c|c|c|}
\hline $\begin{array}{c}\text { Insolation } \\
\text { Level (\%) }\end{array}$ & $\begin{array}{c}\text { Maximum } \\
\text { PVG } \\
\text { Power } \\
\text { Pg, Max } \\
\mathbf{( W )}\end{array}$ & $\begin{array}{c}\mathbf{A} \\
(\boldsymbol{\Omega})\end{array}$ & $\begin{array}{c}\mathbf{B} \\
(\mathbf{1} / \mathbf{A V})\end{array}$ & $\begin{array}{c}\mathbf{C} \\
(\mathbf{1} / \mathbf{A})\end{array}$ \\
\hline 100 & 1388.0 & 12.94 & 0.119 & 0.0819 \\
\hline 90 & 1272 & 13.96 & 0.129 & 0.089 \\
\hline 80 & 1077 & 15.81 & 0.165 & 0.1047 \\
\hline 70 & 910.2 & 17.95 & 0.182 & 0.1198 \\
\hline 60 & 784.7 & 20.01 & 0.209 & 0.1359 \\
\hline 50 & 663.7 & 22.70 & 0.247 & 0.1573 \\
\hline 40 & 456.6 & 29.71 & 0.2386 & 0.2022 \\
\hline
\end{tabular}

\begin{tabular}{|c|c|c|c|}
\hline \multicolumn{4}{|c|}{ Table A-2: Other Parameters Values } \\
\hline AC side & Main AC & Voltage: & Inductance=5 \\
& source & $240 \mathrm{~V}, 50$ & $\mathrm{mH}$ \\
& & $\mathrm{Hz}$ & \\
\cline { 2 - 4 } & Transformer & Resistance $=$ & Inductance $=5$ \\
& & $0 \Omega$ & $\mathrm{mH}$ \\
\cline { 2 - 4 } & AC Load & Resistance $=$ & Inductance= 0 \\
& & $25 \Omega$ & $\mathrm{mH}$ \\
\hline DC side & Smoothing & Resistance $=$ & Inductance $=$ \\
& reactor & $0 \Omega$ & $500 \mathrm{mH}$ \\
\hline
\end{tabular}

\section{A-2: PVG Maximum Power}

The maximum power of the PVG $(\mathrm{Pg}, \max )$ is calculated as follows:

The derivative of equation (4) with respect to the voltage $\mathrm{Vg}$ is found and set to zero.

That is:

$$
\frac{d P_{g}}{d V_{g}}=\frac{d}{d V_{g}}\left[\frac{\left(V_{g}\left(V o c-V_{g}\right)\right.}{A+B V_{g}{ }^{2}-C V_{g}}\right]=0 .
$$

When expanding and simplifying such derivative, the following quadratic equation is expected:

$$
\alpha V^{2}+\beta V+\lambda=0
$$

Where

$$
\begin{aligned}
& \alpha=C-B^{*} \text { Voc }, \quad \beta=-2 A \quad \text { and } \\
& \lambda=A * V o c
\end{aligned}
$$

The solution of equation (A.2) gives the PVG voltage:

$$
V g, \max =\frac{-\beta-\sqrt{\beta^{2}-4 \alpha \lambda}}{-2 \alpha}
$$

The PVG current corresponding to this voltage can be calculated from equation (2) in this paper:

$$
I_{g, \max }=\frac{\left(V O c-V_{g, \text { max }}\right)}{A+B V_{g, \max }^{2}-C V_{g, \max }}
$$

Hence the maximum PVG power (Pg,max) can be calculated as:

$$
P_{g, \text { max }}=V_{g, \text { max }} \frac{\left(V o c-V_{g, \text { max }}\right)}{A+B V_{g, \text { max }}^{2}-C V_{g, \text { max }}}
$$

Based on the Parameters values of Table A.1, the maximum power that can be extracted from the PVG used in this paper at different insolation levels are shown in the second column of Table A.1. 


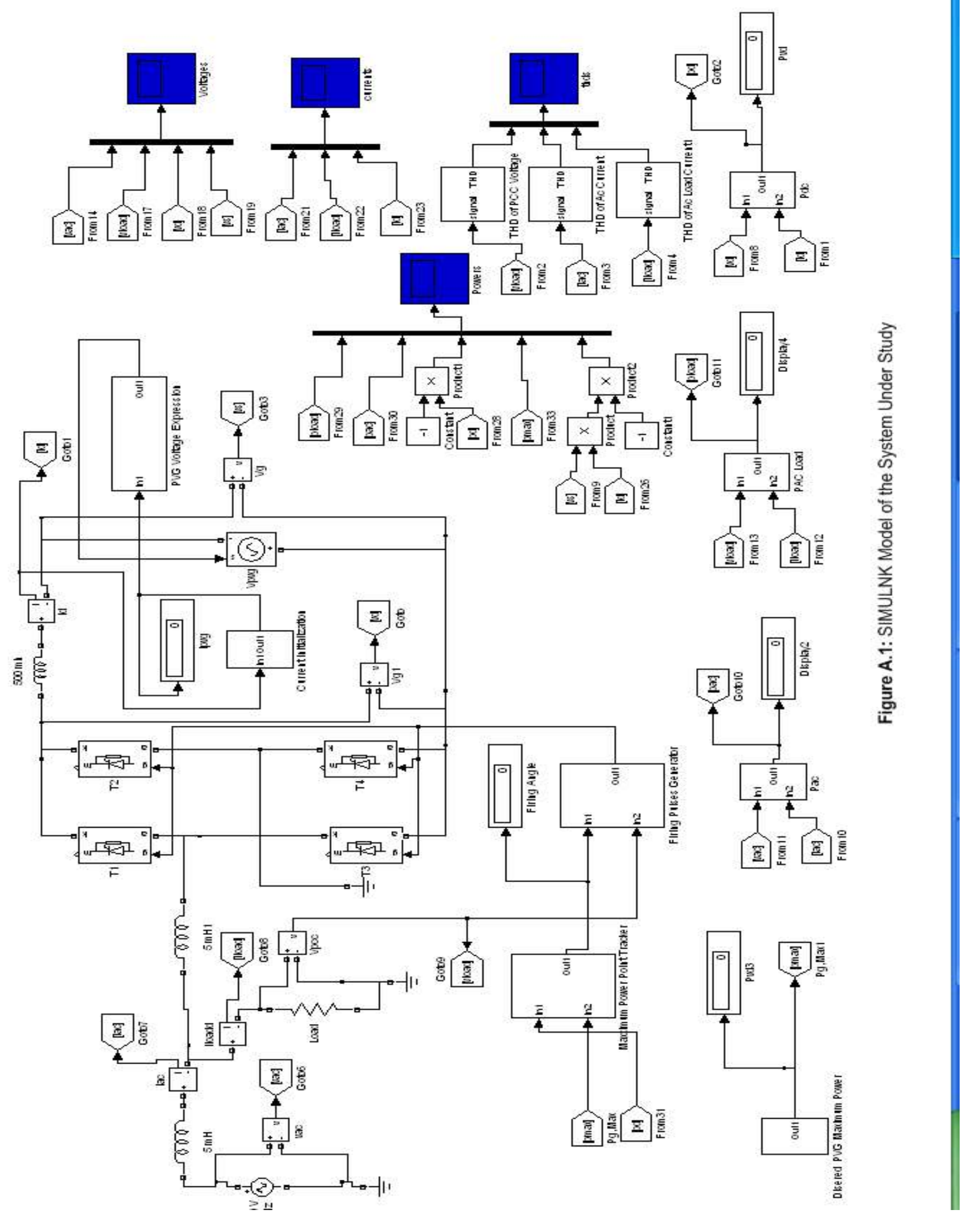

